\title{
Potensi Pengembangan Tanaman Obat-Obatan Di Pekarangan Sebagai Upaya Peningkatan Agroindustri Perkotaan
}

\author{
Ratna Mustika Wardhani \\ Fakultas Pertanian, Universitas Merdeka Madiun, Jl. Serayu No.79, Madiun, 63133 \\ E-mail: ratnamustika@unmer-madiun.ac.id
}

\begin{abstract}
The optimal use of yard is the best solution in providing added value for agro-industry products. One of the raw materials for agro-industry is medicinal plants. This study aims to determine the potential of medicinal plants planted in the yard and analyze the added value of medicinal plants grown in the yard into agro-industrial products. The method used is descriptive method that is applied in several regions that empower fruit, vegetable and medicinal plants as providers of agro-industrial raw materials, while the data analysis method uses the Value-Add Analysis method using the Hayami method (1987). After the research can be concluded as follows: (1) Identification of 15 types of medicinal plants, of which all types of medicinal plants can be used as agroindustry raw materials, namely Ginger, Turmeric, Sere, Pandan, Lengkuas, Aloe Vera, Kencur, Betel, Mustache cat, Tread Doro, Temu lawak, Temu Ireng, Kunci, Keji beling, Sambiroto. (2) Each research area has superior priority for the types of plants used as different raw materials, from the 3 highest priority sequences, namely: Ngawi Regency (Jahe, Kunyit, Sere), Magetan Regency (Ginger, Turmeric, Pandan), Kabupaten Madiun (Ginger, Galangal, Turmeric), Madiun City (Ginger, Pandanus, Sere). (3) Processed products based on medicinal plants, namely Ginger into ginger syrup, are added value of Rp. 20250 - / kg, Turmeric plants become Jamu Kunyit in the amount of Rp. 19500 / kg, Pandanus plants become processed products of Pandan Dye amounting to Rp.46800 / kg.
\end{abstract}

Keywords - : Medicinal Plants; Yard; Agroindustry.

\section{PENDAHULUAN}

Lahan pekarangan dapat dikembangkan sebagai apotik hidup dengan menanami tanaman obat keluarga (TOGA) dan bahan baku agroindustri yang bisa meningkatkan pendapatan keluarga dengan berwirausaha produk olahan dengan memanfaatkan sumberdaya lokal yang diproduksi dari pekarangan. Pemanfaatan Pekarangan yang dikelola melalui pendekatan terpadu berbagai jenis tanaman, ternak dan ikan, sehingga akan menjamin ketersediaan bahan pangan yang beranekaragam secara terus menerus, guna pemenuhan gizi keluarga. Menurut Peny, DH dan Benneth Ginting, 1984, Usaha di pekarangan jika dikelola secara intensif sesuai dengan potensi pekarangan, disamping dapat memenuhi kebutuhan konsumsi rumah tangga, juga dapat memberikan sumbangan pendapatan bagi keluarga. Dari hasil penelitian di Yogyakarta (secara umum pekarangan dapat memberikan sumbangan pendapatan antara 7\% sampai dengan 45\%.. Keberadaan agroindustri pada saat ini semakin diharapkan peranannya untukmeningkatkan perekonomian keluarga, sekaligus sebagai penggerak industrialisasi didaerah . Banyak harapan ditumpukan pada agroindustri, namun keberhasilannya lebih banyak ditentukan oleh potensi yang ada. Dengan pemanfaatan pekarangan diharapkan dapat menjadi penyedia bahan baku agroindustri sehingga dengan pemberdayaan lahan pekarangan selain dapat meningkatkan jiwa kewirausahaan masyarakat juga meningkatkan pendapatan keluarga dengan komoditi yang mendukung agroindustri sebagai produk olahan. Pada umumnya kendala yang dihadapi agroindustri adalah : a). Ketersediaan bahan baku yang tidak kontinyu,(b) proses pengolahan yang menggunakan teknologi sederhana sehingga tidak tahan lama , (c) keterbatasan modal pengrajin untuk penyediaan bahan baku, (d) pemasaran hanya dilakukan secara lokal, sebab pengrajin belum bisa melakukan ekspansi pasar karena tidak adanya kontinyuitas produksi.Masalah yang dihadapi dalam pengembangan agroindustri tidak terlepas daripada pengembangan komoditas, selama ini masih lemahnya keterkaitan antara sektor pertanian dan sektor industri, karena kurang kuatnya kerjasama antar-sektoral yang lebih aktif dalam mengembangkan komoditas serta penyediaan IPTEK budidaya komoditi.

Oleh karena itu dalam pengembangan agroindustri perkotaan perlu diupayakan penberdayaan komoditas yang mendukung melalui pemanfaatan pekarangan di sekitar rumah sehingga kontinyuitas bahan baku dapat teratasi. dan menciptakan struktur agrisbisnis dan agroindustri yang memadai. Dalam penelitian ini akan dikaji potensi dan nilai tambah (value added) tanaman obat-obatan yang dapat mendukung sebagai bahan baku agroindustri perkotaan.

Dengan pemanfaatan pekarangan yang optimal dapat mendukung perkembangan agroindustri melalui ketersediaan bahan baku agroindustri secara kontinyu sehingga dengan bahan baku yang tersedia dalam jumlah dan waktu yang sesuai merupakan syarat kecukupan untuk berproduksi secara berkelanjutan. Jenis tanaman obat-obatan sangat memungkinkan untuk dipergunakan sebagai bahan baku produk olahan . Suprapto (1999) menyatakan bahwa nilai tambah adalah pertambahan nilai suatu komoditas karena mengalami proses pengolahan, pengangkatan, atau penyimpanan dalam suatu produksi. Reni Kustiari 
Website : http://agritek.unmermadiun.ac.id/index.php/agritek

(2011) mengatakan bahwa nilai tambah dalam proses pengolahan dapat didefinisikan sebagai selisih antara nilai produk dengan biaya bahan baku dan input lainnya, tidak termasuk tenaga kerja . Sedangkan marjin adalah selisih antara nilai produk dan harga bahan bakunya saja.Dalam marjin tercakup komponen factor produksi yang digunakan yaitu tenaga kerja, input lainnya, dan balas jasa pengusaha pengolahan.

Nilai tambah yang semakin besar atas produk pertanian tentunya dapat berperan bagi peningkatan pertumbuhan ekonomi. Pertumbuhan ekonomi yang besar tentu saja berdampak bagi peningkatan lapangan usaha dan pendapatan masyarakat yang muara akhirnya adalah meningkatkan kesejahteraan masyarakat. Salah satu fungsi pekarangan sebagai sumber pendapatan dan perbaikan gizi karena pekarangan dapat memberi tambahan pendapatan jika di atur dengan baik. Dengan menanam berbagai tumbuhan dapat memetik dua manfaat sekaligus, yaitu untuk di manfaatkan oleh keluarga dan kelebihannya dapat di jual, terlebih lagi apabila digunakan sebagaai bahan baku agroindustri sehingga hasil tanaman tersebut memperoleh nilai tambah dengan menjadi produk olahan. Adapun tujuan penelitian ini adalah: 1).Mengidentifikasi potensi tanaman obat-obatan di lahan pekarangan sebagai bahan baku agroindustri. 2). Menganalisa nilai tambah komoditas tanaman obat-obatan sebagai bahan baku agroindustri menjadi produk olahan.

\section{METODE PENELITIAN}

\section{A. Lokasi Penelitian}

Sampel Lokasi dipilih secara sengaja (purposive) yang metode yang bersifat tidak acak dan dipilih berdasarkan pertimbangan tertentu (Singarimbun dan Effendi,1989). Lokasi yang dipilih dalam penelitian ini adalah di 4 daerah yaitu Kabupaten Ngawi, Madiun , Magetan dan Kota Madiun, Jawa Timur Indonesia. Adapun Responden penelitian adalah masyarakat yang memberdayakan pekarangan dengan berbagai macam tanaman obat-obatan yang digunakan sebagai penyedia bahan baku agroindustri.Data yang dikumpulkan meliputi data sekunder dan data primer. Data sekunder merupakan data pendukung yang diperoleh dari instansi yang terkait, sedang data primer diperoleh melalui wawancara sejumlah responden dengan menggunakan kuisioner yang telah disiapkan.

\section{B. Metode}

Metode yang digunakan adalah metode deskriptif yang diterapkan di beberapa daerah yang memberdayakan tanaman buah, sayuran dan obat-obatan sebagai penyedia bahan baku agroindustri, berguna untuk menganalisa data-data yang bersifat kualitatif yaitu menggambarkan, meringkas berbagai kondisi, berbagai situasi keadaan tempat penelitian sesuai dengan kondisi lapang, sedangkan metode analisis data menggunakan metode Value-Add Analysis menggunakan metode Hayami (1987) yang berguna untuk mengetahui berapa nilai tambah yang terdapat pada satu kilogram produk olahan. Dari angka ini dapat dihitung berapa pendapat kerja (labour income) yang menunjukkan berapa besar satu kilogram produk olahan memberikan imbalan pendapatan bagi para pekerjanya. Apabila pendapatan kerja terhadap nilai tambah (\%) tinggi, maka agroindustri yang demikian lebih berperan dalam memberikan pendapatan bagi para pekerjanya. Sedangkan sisa nilai tambah yang tidak digunakan sebagai imbalan tenaga kerja merupakan bagian (keuntungan) pengrajin. 
Website : http://agritek.unmermadiun.ac.id/index.php/agritek

Tabel 1. Model Analisis Nilai Tambah dan Pendapatan Kerja Dalam Agroindustri

\begin{tabular}{|c|c|c|}
\hline No & Output,Input dan Harga & Produk olahan \\
\hline $\begin{array}{l}01 \\
02 \\
03 \\
04 \\
05 \\
06 \\
07\end{array}$ & $\begin{array}{l}\text { Hasil Produksi : Produk olahan (kg/bulan) } \\
\text { Bahan Baku : Bahan Baku (kg/bulan) } \\
\text { Tenaga kerja (HK/bulan) } \\
\text { Faktor konversi }(1) /(2) \\
\text { Koefisien Tenaga Kerja (3)/(2) } \\
\text { Harga Produk : Produk olahan (Rp/Kg) } \\
\text { Upah rata-rata (Rp/HK) }\end{array}$ & $\begin{array}{c}\mathrm{A} \\
\mathrm{b} \\
\mathrm{c} \\
\mathrm{a} / \mathrm{b}=\mathrm{m} \\
\mathrm{c} / \mathrm{b}=\mathrm{n} \\
\mathrm{d} \\
\mathrm{e}\end{array}$ \\
\hline \multicolumn{3}{|c|}{ Pendapatan dan Keuntungan (Rp/kg input bahan baku) } \\
\hline $\begin{array}{l}08 \\
09 \\
10 \\
11 \\
12 \\
13 \\
14 \\
15 \\
16\end{array}$ & $\begin{array}{l}\text { Input: bahan baku }(\mathrm{Rp} / \mathrm{kg}) \\
\text { Input lain : bahan tambahan }(\mathrm{Rp} / \mathrm{kg} \text { bahan baku) } \\
\text { Nilai Produksi }(\mathrm{Rp} / \mathrm{kg}=\text { faktor konvensi x harga produk } \\
\text { olahan) } \\
\text { Nilai tambah per } \mathbf{k g} \text { bahan baku }(\mathbf{1 0 - 0 9 - 0 8 )} \\
\text { Rasio nilai tambah }(11 / 10 \times 100 \%) \\
\text { Imbalan kerja }(\mathrm{Rp} / \mathrm{kg} \text { bahan baku = koefisien kerja x upah } \\
\text { rata-rata) } \\
\text { Rasio bagian tenaga kerja }(13 / 11 \times 100 \%) \\
\text { Keuntungan pengolah }(11-13) \\
\text { Tingkat Keuntungan pengolah }(15 / 11 \times 100 \%)\end{array}$ & $\begin{array}{l}\qquad \begin{array}{c}\mathrm{F} \\
\mathrm{m} \times \mathrm{d}=\mathrm{k}\end{array} \\
\mathrm{k}-\mathrm{f}-\mathrm{g}=\mathrm{i} \\
\mathrm{i} / \mathrm{k} \times 100 \%=\mathrm{h} \% \\
\mathrm{n} \times \mathrm{I}=\mathrm{p} \\
\mathrm{p} / \mathrm{I} \times 100 \%=\mathrm{q} \% \\
\mathrm{i}-\mathrm{p}=\mathrm{r} \\
\mathrm{r} / \mathrm{I} \times 100 \%=\mathrm{s} \%\end{array}$ \\
\hline
\end{tabular}

\section{III.HASIL DAN PEMBAHASAN}

\section{A. Diskripsi Daerah Penelitian}

1. Kabupeten Ngawi.

Kabupaten Ngawi terletak di wilayah barat Propinsi Jawa Timur.Berbatasan langsung dengan Propinsi Jawa Tengah. Secara geografis Kabupaten Ngawi terletak pada posisi $110^{\circ} 10^{\prime}-111^{\circ} 40^{\prime}$ Bujur Timur dan $7^{\circ} 21^{\prime}-7^{\circ} 31^{\prime}$ Lintang Selatan.Batas wilayah Kabupaten Ngawi adalah sebagai berikut:

- Sebelah Utara : Kabupaten Grobogan, Kabupaten Blora (Propinsi Jawa Tengah) dan Kabupaten Bojonegoro.

- Sebelah Timur : Kabupaten Madiun.

- Sebelah Selatan : Kabupaten Madiun dan Kabupaten Magetan.

- Sebelah Barat : Kabupaten Karanganyar dan Kabupaten Sragen (Propinsi Jawa Tengah).

Secara administrasi wilayah ini terbagi ke dalam 19 Kecamatan dan 217 desa, dimana 4 dari 217 desa tersebut adalah kelurahan. Luas wilayah Kabupaten Ngawi adalah 1.295,58 km2, di mana sekitar 39 persen atau sekitar 504,76 km2 berupa lahan sawah.

\section{Kabupaten Magetan}

Lokasi Magetan merupakan kabupaten yang terletak di ujung barat Propinsi Jawa Timur, dan berada pada ketinggian antara 60 sampai dengan 1.660 meter diatas permukaan laut.Magetan merupakan kabupaten terkecil ke dua se-Jawa Timursetelah Sidoarjo, dengan luas seluruh Kabupaten Magetan 688,85km2. Kecamatan Parang merupakan kecamatan terluas dengan luas71,64 Km2, sedang Karangrejo dengan luas 15,15 Km2 merupakan kecamatan dengan luas terkecil.Dengan 18 kecamatanyang ada di Kabupaten Magetan, berarti rata-rata luas tiap kecamatan sebesar 38,27 Km2. Jarak antar ibu kota kecamatan yang tidak terlalu jauh merupakan salah satu faktor yang menguntungkan untuk melaksanakan pembangunan. Jarak terpendek adalah Kecamatan Poncol-Plaosan yang berjarak 3,4 Km dan jarak terjauh Kecamatan Parang-Kartoharjo sejauh $41 \mathrm{Km}$. Sedang Jarak terpendek dari ibukota kabupaten ke kecamatan, adalah dengan Kecamatan Magetan sejauh 2 km dan jarak terjauh adalah dengan Kecamatan Kartoharjo dengan jarak 26 Km.

\section{Kabupaten Madiun}

Secara geografis Kabupaten Madiun terletak di sekitar $7^{\circ} 12^{\prime}-7^{\circ} 48^{\prime} 30^{\prime \prime}$ Lintang Selatan dan $111^{\circ} 25^{\prime} 45^{\prime}$ ' $-111^{\circ} 51^{\prime}$ Bujur Timur. Dengan Luas wilayah Kabupaten Madiun 1.010,86 Km².Secara administratif, kabupaten Madiun ini 
Website : http://agritek.unmermadiun.ac.id/index.php/agritek

terbagi menjadi lima belas Kecamatan, 206 Desa dan kelurahan. Kabupaten ini memiliki jumlah penduduk sebesar 661.886 jiwa (sensus penduduk 2010).

Keseluruhan luas wilayah $1.010,86 \mathrm{Km}^{2}$ dengan batas-batas sebagai berikut:

Sebelah utara : Kabupaten Bojonegoro.

Sebelah timur : Kabupaten Nganjuk.

Sebelah selatan : Kabupaten Ponorogo.

Sebelah barat : Kabupaten Magetan dan Kabupaten Ngawi.

Bagian utara wilayah Madiun berupa perbukitan, yakni bagian dari rangkaian Pegunungan Kendeng.Bagian tengah merupakan dataran tinggi dan bergelombang.Sedang bagian tenggara berupa pegunungan, bagian dari kompleks Gunung Wilis-Gunung Liman.

Jarak antara Kabupaten Madiun dengan Ibukota Provinsi Jawa Timur (Surabaya) kurang lebih 175 Km ke arah timur, sedangkan jarak dengan ibukota negara kurang lebih $775 \mathrm{Km}$ dengan arah sebaliknya.

\section{Kota Madiun}

Kota Madiun merupakandataran rendah dengan ketinggian rata-rata $\pm 70 \mathrm{~m}$ diatas permukaan laut, terletak pada posisi $7^{\circ}-8^{\circ}$ lintang selatan, serta $111^{\circ}-112^{\circ}$ Bujur Timur. Secara keseluruhan wilayah Kota Madiun berupa dartan dengan luas $33,23 \mathrm{~km}^{2}$. Wilayah ada Kota Madiun terdiri atas 3 wilayah kecamatan yaitu Kecamatan Manguharjo $\left(10.04 \mathrm{~km}^{2}\right)$, Kecamatan Taman $\left(12.46 \mathrm{~km}^{2}\right)$ dan Kecamatan Kartoharjo $\left(10.73 \mathrm{~km}^{2}\right)$. Suhu udara Kota Madiun tergolong sejuk yaitu rata-rata suhu udara selama tahun 2015 di Kota Madiun adalah $24^{\circ} \mathrm{C}$ dengan kelembaban udara sekitar $24 \%$.

Keadaan pertanian di Kota Madiun pada tahun 2015 luas lahan sawah 1041 Ha. Sedangkan luas tegal atau pekarangan di Kota Madiun 152 Ha yang terdiri dari : Kecamatan Manguharjo sebanyak 45 Ha, Kecamatan Taman sebanyak 60 Ha dan Kecamatan Kartoharjo sebanyak 47 Ha.

\section{B. Perkembangan Tanaman Obat-obatan di Pekarangan .}

Dari hasil survey yang telah dilakukan di lokasi penelitian maka dapat diketahui bahwa tanaman obat-obatan yang ditanam di pekarangan pada Kabupaten Ngawi, Magetan, Madiun dan Kota Madiun sebanyak 15 jenis tanaman. Budidaya jenis tanaman obat-obatan yang ditanam di pekarangan lebih mudah dari pada tanaman obat-obatan, hal ini dikarenakan tanaman obat-obatan lebih mudah cara budidayanya. Kemudian setelah dilakukan inventarisasi dan identifikasi pendapat para pakar dengan dasar kriteria pemilihan potensi pengembangan tanaman buah yaitu meliputi luas lahan, produksi, jenis tanaman, kemudahan budidaya, daya tarik masyarakat untuk menanam, daya simpan, kontinuitas ketersediaan maka dari 15 jenis tanaman obatobatan dapat mendukung sebagai bahan baku agroindustri. Pada grafik dibawah menunjukkan jumlah responden dan jenis tanaman obat-obatan yang ditanam pada pekarangan:

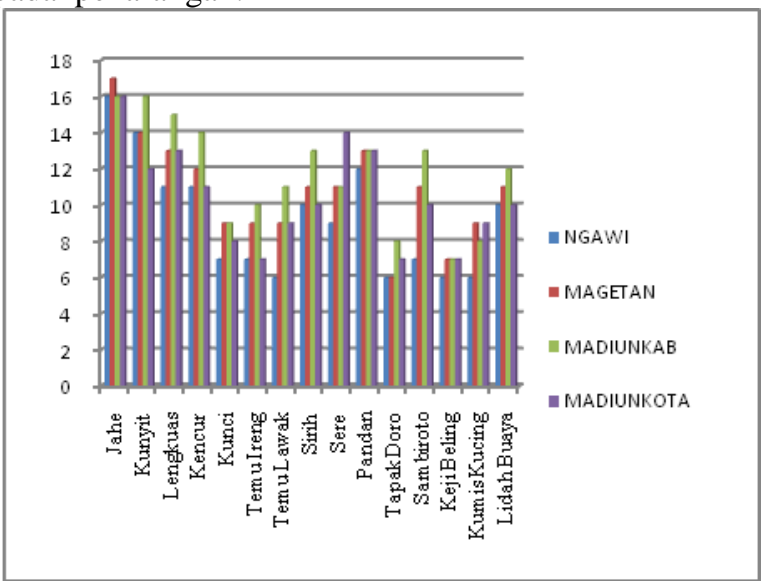

Grafik 1. Jumlah Responden dan Jenis Tanaman Obat-obatan yang ditanam di Pekarangan

Dari grafik diatas dapat diketahui bahwa jumlah penanam tanaman obat-obatan di kabupaten Madiun menunjukkan jumlah penanam yang besar yaitu menanam tanaman jahe, kunyit, lengkuas, kencur, sirih, pandan, lidah buaya, hal ini disebabkan karena budidaya tanaman obat-obatan lebih mudah dari pada budidaya tanaman sayuran yaitu lebih mudah menyesuaikan dengan lingkungan sehingga tanaman obat-obatan di Kabupaten Madiun banyak yang menanam di pekarangan. Demikian juga pada Kabupaten Ngawi, Magetan maupun Madiun Kota yang paling banyak penanam tanaman obat-obatan yaitu tanaman jahe, kunyit, kencur,pandan, sere, dan lidah buaya. 
Website : http://agritek.unmermadiun.ac.id/index.php/agritek

\section{Prioritas Jenis Tanaman Obat-obatan yang ditanam di Pekarangan}

Berbagai jenis tanaman obat-obatan (TOGA) yang telah ditanam pada pekarangan rumah di daerah penelitian yaitu Kabupaten Ngawi, Kabupaten Magetan, Kabupaten Madiun dan Kota Madiun, diperoleh hasil bahwa jenis-jenis tanaman obatobatan yang ditanam masyarakat pada masing-masing pekarangan rumah adalah berbeda-beda, hal ini menunjukkan bahwa potensi masing-masing daerah penelitian terhadap tanaman obat-obatan adalah berbeda. Berikut pritoritas jenis tanaman obatobatan yang ditanam di pekarangan setelah dilakukan uji MPE diperoleh hasil sebagai berikut :

Tabel.2 Prioritas Jenis Tanaman Obat-Obatan (Toga) Yang Ditanam Di Pekarangan

\begin{tabular}{|c|c|c|c|c|c|c|c|c|c|}
\hline \multirow{2}{*}{ No } & \multicolumn{9}{|c|}{ Prioritas Potensi pengembangan tanaman obat-obatan sebagai bahan baku agroindustri dengan MPE } \\
\cline { 2 - 9 } & \multirow{2}{*}{ Jenis Tanaman } & \multicolumn{2}{|c|}{ Ngawi } & \multicolumn{2}{c|}{ Magetan Madiun Kab } & \multicolumn{2}{c|}{ MadiunKota } \\
\cline { 2 - 9 } & Nilai MPE & Prioritas & Nilai MPE & Prioritas & Nilai MPE & Prioritas & Nilai MPE & Prioritas \\
\hline 1 & Jahe & 29174948 & 1 & 65638370 & 1 & 67252240 & 1 & 54669328 & 1 \\
\hline 2 & Kunyit & 20643986 & 2 & 29310866 & 2 & 21523194 & 3 & 11515751 & 7 \\
\hline 3 & Sere & 17441555 & 3 & 17783696 & 4 & 17785779,7 & 5 & 17786223,5 & 3 \\
\hline 4 & Pandan & 6611808 & 4 & 18889146 & 3 & 18903603 & 4 & 26081255,5 & 2 \\
\hline 5 & Sirih & 6610069 & 5 & 6596524 & 8 & 8707815,96 & 8 & 8707816 & 8 \\
\hline 6 & Lidah Buaya & 6610069 & 6 & 11560963 & 6 & 11682508 & 7 & 17390557,7 & 5 \\
\hline 7 & Kencur & 5258028 & 7 & 8219175 & 7 & 16730401 & 6 & 17497703 & 4 \\
\hline 8 & Lengkuas & 5256289 & 8 & 16217667 & 5 & 28513907 & 2 & 16728345 & 6 \\
\hline 9 & Kumis kucing & 2280263 & 9 & 2278330 & 9 & 2280413,73 & 10 & 2280857 & 10 \\
\hline 10 & Tapak Doro & 2279890 & 10 & 2277957 & 10 & 2280041,09 & 11 & 2280041,09 & 11 \\
\hline 11 & Temu lawak & 926483 & 11 & 1186694 & 11 & 1713065 & 12 & 1188777 & 13 \\
\hline 12 & Temu Ireng & 788410 & 12 & 1037008 & 12 & 1030168 & 14 & 1030168 & 14 \\
\hline 13 & Keji beling & 751269 & 13 & 749336 & 14 & 752180,615 & 15 & 777921,41 & 15 \\
\hline 14 & Kunci & 749530 & 14 & 1009741 & 13 & 1037565 & 13 & 1612610 & 12 \\
\hline 15 & Sambiroto & 743050 & 15 & 742785 & 15 & 2571283,69 & 9 & 2747863,75 & 9 \\
\hline 5
\end{tabular}

Sumber : Data Primer diolah

Dari table diatas dapat diketahui bahwa tanaman obat-obatan yang ditanam di daerah penelitian (Kabupaten Ngawi, Magetan, Madiun dan Kota Madiun) untuk prioritas potensi yang tertinggi adalah tanaman Jahe, sedangkan untuk prioritas potensi pengembangan tanaman obat-obatan yang ke 2 adalah tanaman Kunyit yang banyak ditanam di Kabupaten Ngawi dan Magetan , adapun Kabupaten Madiun prioritas potensi tanaman obat-obatan adalah tanaman Lengkuas dan Kota Madiun prioritas potensinya adalah tanaman Pandan. Untuk prioritas potensi pengembangan tanaman obat-obatan yang ke 3 pada masing-masing daerah penelitian adalah berbeda-beda, di Kabupaten Ngawi dan Kota Madiun prioritas potensi ke 3 adalah tanaman Sere, sedangkan untuk Kabupaten Magetan adalah tanaman Pandan dan Kabupaten Madiun adalah tanaman Kunyit.

\section{Prioritas Pengembangan Agroindustri dengan Bahan Baku Tanaman Obat-obatan}

Dalam pengembangan agroindustri pada daerah penelitian perlu diperhatikan produk olahan yang bisa dipergunakan pada masing-masing bahan baku yang berasal dari tanaman obat-obatan (TOGA) pada masing-masing daerah penelitian. Prioritas yang dapat diketahui untuk pengembangan agroindustri dapat diketahui dari pendapat para pakar yang terdiri dari : pengusaha agroindustri, akademisi, dan instansi yang terkait. Berikut Prioritas pemilihan potensi pengembangan Agroindustri setelah dilakukan uji MPE sesuai dengan potensi tanaman obat-obatan (TOGA) yang ada pada masing-masing daerah penelitian dapat diketahui sebagai berikut :

\section{a. Daerah Kabupaten Ngawi}

Tabel 3. Prioritas Pemilihan Agroindustri dengan Bahan Baku Tanaman Obat-obatan di Kab. Ngawi

\begin{tabular}{|c|c|c|c|c|c|c|c|}
\hline \multirow{3}{*}{ No } & \multirow{3}{*}{$\begin{array}{l}\text { Jenis Produk } \\
\text { Olahan }\end{array}$} & \multicolumn{6}{|c|}{$\begin{array}{c}\text { Prioritas Potensi Pengembangan Agroindustri dengan Bahan Baku } \\
\text { Tanaman Obat-obatan }\end{array}$} \\
\hline & & \multicolumn{2}{|c|}{$\begin{array}{l}\text { Bahan Baku } \\
\text { Jahe }\end{array}$} & \multicolumn{2}{|c|}{ Bahan Baku Kunyit } & \multicolumn{2}{|c|}{ Bahan Baku Sere } \\
\hline & & $\begin{array}{l}\text { Nilai } \\
\text { MPE }\end{array}$ & $\begin{array}{l}\text { Prior } \\
\text { itas }\end{array}$ & $\begin{array}{l}\text { Nilai } \\
\text { MPE }\end{array}$ & Prioritas & $\begin{array}{c}\text { Nilai } \\
\text { MP }\end{array}$ & Prioritas \\
\hline
\end{tabular}

Volume 21 Nomor 2 September 2020, AGRI-TEK | 88 
Website : http://agritek.unmermadiun.ac.id/index.php/agritek

\begin{tabular}{|c|c|c|c|c|c|c|c|}
\hline & & & & & & $\mathbf{E}$ & \\
\hline 1 & Jamu & $\begin{array}{r}6559753 \\
5\end{array}$ & 1 & $\begin{array}{r}18245 \\
5673\end{array}$ & 1 & 0 & 0 \\
\hline 2 & Jual Segar & $\begin{array}{r}4684546 \\
4\end{array}$ & 2 & $\begin{array}{r}89933 \\
203\end{array}$ & 3 & $\begin{array}{l}3547 \\
6001\end{array}$ & 3 \\
\hline 3 & Sirup & $\begin{array}{r}3243149 \\
5 \\
\end{array}$ & 3 & 0 & 0 & $\begin{array}{l}9594 \\
9368\end{array}$ & 1 \\
\hline 4 & Jahe Instan & $\begin{array}{r}1619323 \\
4\end{array}$ & 4 & 0 & 0 & 0 & 0 \\
\hline 5 & Permen & 7026508 & 5 & 0 & 0 & 0 & 0 \\
\hline 6 & Olahan Bumbu & 0 & 0 & $\begin{array}{r}11357 \\
4410 \\
\end{array}$ & 2 & $\begin{array}{l}5084 \\
0928 \\
\end{array}$ & 2 \\
\hline 7 & Pewarna & 0 & 0 & $\begin{array}{r}68824 \\
125\end{array}$ & 4 & 0 & 0 \\
\hline
\end{tabular}

Dari tabel diatas menunjukkan bahwa di Kabupaten Ngawi untuk prioritas pemilihan agroindustri dengan bahan baku tanaman obat-obatan (TOGA) adalah Tanaman Jahe, Kunyit dan Sere, hal ini menunjukkan bahwa ke 3 tanaman obat-obatan tersebut paling panyak dibudidayakan di pekarangan Kabupaten Ngawi. Sedangkan pemilihan agroindustri yang berdasarkan bahan baku tersebut diatas dapat diketahui sesuai prioritas dari berbagai macam jenis produk olahan (agroindustri) selain itu seringkali di jual dalam bentuk primer atau segar, hal ini dilakukan karena untuk segera masyarakat mendapatkan pendapatan dan kurang telatennya masyarakat menjadikan produk olahan. Bahan baku Tanaman Jahe secara prioritas dapat diketahui bahwa prioritas tertinggi digunakan sebagai bahan baku olahan Jamu, sebagian ada yang langsung dijual dalam bentuk segar, berikutnya diolah menjadi Sirup Jahe, Jahe Instan dan dibuat Permen (enting-enting). Sedangkan tanaman Kunyit sesuai prioritasnya dapat diolah menjadi Jamu, kemudian olahan yang lain sebagai pewarna masakan (Warna kuning), berikutnya masyarakat memilih dijual dalam bentuk primer atau segar dan olahan yang lain adalah sebagai olahan bumbu masakan yang sudah siap dimasak. Adapun tanaman Sere sesuai prioritas pemilihan dapat diketahui prioritas pertama diolah menjadi bahan tambahan Sirup dan selanjutnya diolah menjadi bahan tambahan olahan bumbu dan banyak juga masyarakat menjual secara primer atau dalam bentuk segar.

\section{b. Daerah Kabupaten Magetan}

Tabel 4. Prioritas Pemilihan Agroindustri dengan Bahan Baku Tanaman Obat-obatan di Magetan

\begin{tabular}{|c|c|c|c|c|c|c|c|}
\hline \multirow{3}{*}{ No } & \multirow{3}{*}{$\begin{array}{l}\text { Jenis Produk } \\
\text { Olahan }\end{array}$} & \multicolumn{6}{|c|}{ Prioritas Potensi Pengembangan Agroindustri dengan Bahan Baku Tanaman Obat-obatan } \\
\hline & & \multicolumn{2}{|c|}{ Bahan Baku Jahe } & \multicolumn{2}{|c|}{ Bahan Baku Kunyit } & \multicolumn{2}{|c|}{ Bahan Baku Pandan } \\
\hline & & Nilai MPE & Prioritas & Nilai MPE & Prioritas & Nilai MPE & Prioritas \\
\hline 1 & Permen & 65471090 & 1 & 0 & 0 & 0 & 0 \\
\hline 2 & Jahe Instan & 57515129 & 2 & 0 & 0 & 0 & 0 \\
\hline 3 & Sirup & 32431495 & 3 & 0 & 0 & 41057170 & 2 \\
\hline 4 & Jamu & 29343750 & 4 & 113541635 & 2 & 0 & 0 \\
\hline 5 & Jual Segar & 23134024 & 5 & 56975506 & 4 & 32221007 & 3 \\
\hline 6 & Olahan Bumbu & 0 & 0 & 90365019 & 3 & 0 & 0 \\
\hline 7 & Pewarna & 0 & 0 & 141162022 & 1 & 57295749 & 1 \\
\hline
\end{tabular}

Dari tabel diatas menunjukkan bahwa di Kabupaten Magetan untuk prioritas pemilihan agroindustri dengan bahan baku tanaman obat-obatan (TOGA) adalah Tanaman Jahe, Kunyit dan Pandan, hal ini menunjukkan bahwa ke 3 tanaman obat-obatan tersebut paling panyak dibudidayakan di pekarangan Kabupaten Magetan. Sedangkan pemilihan agroindustri yang berdasarkan bahan baku tersebut diatas dapat diketahui sesuai prioritas dari berbagai macam jenis produk olahan (agroindustri) selain itu seringkali di jual dalam bentuk primer atau segar, hal ini dilakukan karena untuk segera masyarakat mendapatkan pendapatan dan kurang telatennya masyarakat menjadikan produk olahan. Bahan baku Tanaman Jahe secara prioritas dapat diketahui bahwa prioritas tertinggi digunakan sebagai bahan baku olahan Permen, sebagian ada yang langsung dijual dalam bentuk segar, berikutnya diolah menjadi Jahe Instan, Sirup Jahe, Jamu dan di jual segar. Sedangkan tanaman Kunyit sesuai prioritasnya dapat diolah menjadi pewarna masakan (Warna kuning), kemudian olahan yang lain sebagai Jamu, dan olahan yang lain adalah sebagai olahan bumbu masakan yang sudah siap dimasak, berikutnya masyarakat memilih dijual dalam bentuk primer atau 
Website : http://agritek.unmermadiun.ac.id/index.php/agritek

segar. Adapun tanaman Pandan sesuai prioritas pemilihan dapat diketahui prioritas pertama diolah menjadi pewarna masakan (warna hijau), selanjutnya diolah menjadi bahan tambahan Sirup dan banyak juga masyarakat menjual secara primer atau dalam bentuk segar.

\section{c. Daerah Kabupaten Madiun}

Tabel 5. Prioritas Pemilihan Agroindustri dengan Bahan Baku Tanaman Obat-obatan di Kab.Madiun

\begin{tabular}{|c|c|c|c|c|c|c|c|}
\hline \multirow{3}{*}{ No } & \multirow{3}{*}{$\begin{array}{c}\text { Jenis } \\
\text { Produk } \\
\text { Olahan }\end{array}$} & \multicolumn{6}{|c|}{$\begin{array}{c}\text { Prioritas Potensi Pengembangan Agroindustri dengan Bahan Baku Tanaman Obat- } \\
\text { obatan }\end{array}$} \\
\hline & & \multicolumn{2}{|c|}{ Bahan Baku Jahe } & \multicolumn{2}{|c|}{$\begin{array}{l}\text { Bahan Baku } \\
\text { Lengkuas }\end{array}$} & \multicolumn{2}{|c|}{ Bahan Baku Kunyit } \\
\hline & & Nilai MPE & Prioritas & $\begin{array}{l}\text { Nilai } \\
\text { MPE }\end{array}$ & $\begin{array}{l}\text { Prio } \\
\text { ritas }\end{array}$ & Nilai MPE & Prioritas \\
\hline 1 & Sirup & 57286365 & 1 & 0 & 0 & 0 & 0 \\
\hline 2 & Jual Segar & 37169626 & 2 & $\begin{array}{c}26829 \\
626\end{array}$ & 1 & 169248152 & 3 \\
\hline 3 & Jamu & 32926416 & 3 & 0 & 0 & 201637652 & 1 \\
\hline 4 & Jahe Instan & 16193234 & 4 & 0 & 0 & 0 & 0 \\
\hline 5 & Permen & 7026508 & 5 & 0 & 0 & 0 & 0 \\
\hline 6 & $\begin{array}{l}\text { Olahan } \\
\text { Bumbu }\end{array}$ & 0 & 0 & $\begin{array}{c}26827 \\
126\end{array}$ & 2 & 103173861 & 4 \\
\hline 7 & Pewarna & 0 & 0 & 0 & 0 & 170235725 & 2 \\
\hline 8 & Obat Herbal & 0 & 0 & $\begin{array}{c}56828 \\
41\end{array}$ & 3 & 0 & 0 \\
\hline
\end{tabular}

Dari table diatas menunjukkan bahwa di Kabupaten Madiun untuk prioritas pemilihan agroindustri dengan bahan baku tanaman obat-obatan (TOGA) adalah Tanaman Jahe, Lengkuas dan Kunyit, hal ini menunjukkan bahwa ke 3 tanaman obatobatan tersebut paling panyak dibudidayakan di pekarangan Kabupaten Madiun. Sedangkan pemilihan agroindustri yang berdasarkan bahan baku tersebut diatas dapat diketahui sesuai prioritas dari berbagai macam jenis produk olahan (agroindustri) selain itu seringkali di jual dalam bentuk primer atau segar, hal ini dilakukan karena untuk segera masyarakat mendapatkan pendapatan dan kurang telatennya masyarakat menjadikan produk olahan. Tanaman Jahe secara prioritas dapat diketahui bahwa prioritas tertinggi digunakan sebagai bahan baku olahan Jamu, sebagian ada yang langsung dijual dalam bentuk segar, berikutnya diolah menjadi Sirup Jahe, Jahe Instan dan dibuat Permen (enting-enting). Sedangkan tanaman Lengkuas sesuai prioritas pemilihan dapat diketahui prioritas pertama banyak masyarakat yang menjual secara primer atau dalam bentuk segar, kemudian prioritas berikutnya lengkuas diolah menjadi bahan tambahan olahan bumbu yang siap untuk memasak, prioritas selanjutnya bahwa lengkuas dapat diolah menjadi obat herbal (obat kulit). Adapun tanaman Kunyit sesuai prioritasnya dapat diolah menjadi Jamu kemudian olahan yang lain sebagai pewarna masakan (Warna kuning), dan prioritas berikutnya masyarakat memilih dijual dalam bentuk primer atau segar, selanjutnya olahan bumbu masakan yang sudah siap dimasak merupakan prioritas ke 4 .

\section{d. Daerah Kota Madiun}

Tabel 6. Prioritas Pemilihan Agroindustri dengan Bahan Baku Tanaman Obat-obatan di Kota Madiun

\begin{tabular}{|c|c|c|c|c|c|c|c|}
\hline \multirow{3}{*}{ No } & \multirow{3}{*}{$\begin{array}{c}\text { Jenis } \\
\text { Produk } \\
\text { Olahan }\end{array}$} & \multicolumn{6}{|c|}{$\begin{array}{l}\text { Prioritas Potensi Pengembangan Agroindustri dengan Bahan Baku } \\
\text { Tanaman Obat-obatan }\end{array}$} \\
\hline & & \multicolumn{2}{|c|}{ Bahan Baku Jahe } & \multicolumn{2}{|c|}{ Bahan Baku Pandan } & \multicolumn{2}{|c|}{ Bahan Baku Sere } \\
\hline & & Nilai MPE & Prioritas & $\begin{array}{l}\text { Nilai } \\
\text { MPE }\end{array}$ & Prioritas & $\begin{array}{l}\text { Nilai } \\
\text { MPE }\end{array}$ & Prioritas \\
\hline 1 & Sirup & 65775716 & 1 & 78091061 & 3 & $\begin{array}{r}321763 \\
95\end{array}$ & 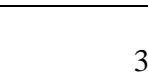 \\
\hline 2 & Jamu & 41703479 & 2 & 0 & 0 & 0 & 0 \\
\hline & & & & 11347099 & & 419724 & \\
\hline 3 & Jual Segar & 33976713 & 3 & 8 & 1 & 44 & 1 \\
\hline 4 & Jahe Instan & 21364037 & 4 & 0 & 0 & 0 & 0 \\
\hline 5 & Permen & 7026508 & 5 & 0 & 0 & 0 & 0 \\
\hline 6 & Olahan & 0 & 0 & 0 & 0 & 321822 & 2 \\
\hline
\end{tabular}

Volume 21 Nomor 2 September 2020, AGRI-TEK | 90 
Website : http://agritek.unmermadiun.ac.id/index.php/agritek

\begin{tabular}{r|r|r|r|r|r|r|r|} 
& Bumbu & & & & 67 & \\
\hline 7 & Pewarna & 0 & 0 & 91235321 & 2 & 0 & 0 \\
\hline
\end{tabular}

Dari table diatas menunjukkan bahwa di Kota Madiun untuk prioritas pemilihan agroindustri dengan bahan baku tanaman obat-obatan (TOGA) adalah Tanaman Jahe, Pandan dan Sere, hal ini menunjukkan bahwa ke 3 tanaman obat-obatan tersebut paling panyak dibudidayakan di pekarangan Kota Madiun. Sedangkan pemilihan agroindustri yang berdasarkan bahan baku tersebut diatas dapat diketahui sesuai prioritas dari berbagai macam jenis produk olahan (agroindustri) selain itu seringkali di jual dalam bentuk primer atau segar, hal ini dilakukan karena untuk segera masyarakat mendapatkan pendapatan dan kurang telatennya masyarakat menjadikan produk olahan. Tanaman Jahe secara prioritas dapat diketahui bahwa prioritas tertinggi digunakan sebagai bahan baku olahan Sirup Jahe, bentuk olahan selanjutnya yaitu sebagai Jamu, sebagian ada yang langsung dijual dalam bentuk segar, berikutnya diolah menjadi, Jahe Instan dan dibuat Permen (enting-enting). Tanaman obat-obatan selanjutnya yang dibudidayakan di Kota Madiun sebagai bahan baku agroindustri adalah tanaman Pandan , prioritas pertama tanaman Pandan masih dijual secara primer atau dalam bentuk segar, prioritas berikutnya pandan dapat diolah sebagai pewarna masakan alami (Warna Hijau), dan selanjutnya pandan dapat diolah sebagai bahan tambahan Sirup. Adapun tanaman Sere juga masih banyak dijual secara primer atau segar, kemudian prioritas selanjutnya dapat digunakan sebagai bahan tambahan olahan bumbu siap dimasak, selanjutnya prioritas produk olahan yang lain sebagai bahan tambahan Sirup.

\section{Potensi dan Nilai Tambah Tanaman Obat-obatan.}

a. Potensi Tanaman Obat-obatan yang ditanam pada pekarangan.

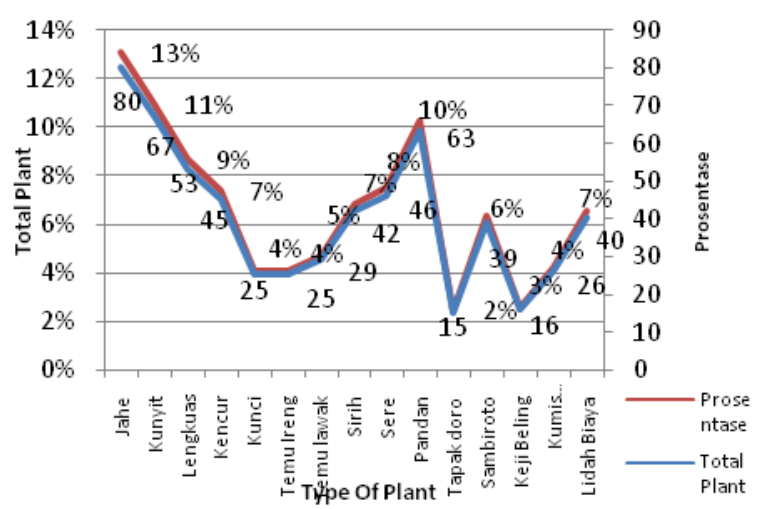

Dari diagram diatas dapat diketahui bahwa jumlah jenis tanaman obat-obatan yang ditanam pada pekarangan sebanyak 15 jenis tanaman dengan jumlah 611 tanaman. Dari 15 jenis tanaman obat-obatan tersebut 3 tanaman obat-obatan yang mempunyai prosentase tertinggi dari seluruh jumlah tanaman buah yang ditanam untuk dapat dilakukan pengolahan lebih lanjut yaitu tanaman Jahe sebanyak 80 pohon (13\%), kemudian dikuti tanaman Kunyit sebanyak 67 (11\%) dan tanaman obat-obatan yang banyak ditanam di lahan pekarangan adalah tanaman Pandan sebanyak63 atau $10 \%$

b. Nilai Tambah dari tanaman Obat-obatan.

Dari tanaman obat-obatan yang banyak ditanam di lahan pekarangan selanjutnya dapat diolah menjadi produk olahan sehingga diharapkan diperoleh nilai tambah. Adapun tanaman obat-obatan yang dapat diolah menjadi produk olahan adalah tanaman Jahe menjadi produk olahan Sirup Jahe, sedangkan tanaman Kunyit dapat diolah menjadi Jamu Kunyit, adapun tanaman pandan dapat diolah menjadi pewarna pandan, hal ini disajikan pada tabel berikut :

Tabel 7. Analisa Nilai Tambah Berbahan Baku Tanaman Obat-obatan

\begin{tabular}{clrrr}
\hline NO & \multicolumn{1}{c}{$\begin{array}{c}\text { Keluaran (Output), Masukan (Input) dan } \\
\text { Harga }\end{array}$} & $\begin{array}{c}\text { Sirup } \\
\text { Jahe }\end{array}$ & $\begin{array}{c}\text { Jamu } \\
\text { Kunyit }\end{array}$ & $\begin{array}{c}\text { Pewarna } \\
\text { Pandan }\end{array}$ \\
\hline 1 & Output yang dihasilkan (Kg/proses produksi) & 25 & 40 & 30 \\
2 & Input Bahan Baku (Kg/proses produksi) & 60 & 80 & 75 \\
3 & Input Tenaga Kerja (HOK/proses produksi) & 4 & 6 & 5 \\
4 & Faktor konversi (Kg output/Kg bahan baku) & 0,417 & 0,5 & 0,4 \\
5 & Koefisien Tenaga Kerja (HOK/Kg bahan baku) & 0,067 & 0,075 & 0,067 \\
6 & Harga output (Rp/Kg) & 75000 & 60000 & 130000
\end{tabular}

Volume 21 Nomor 2 September 2020, AGRI-TEK | 91 
Website : http://agritek.unmermadiun.ac.id/index.php/agritek

\begin{tabular}{|c|c|c|c|c|}
\hline 7 & $\begin{array}{l}\text { Upah rata-rata Tenaga Kerja (Rp/proses } \\
\text { produksi) }\end{array}$ & 20000 & 17500 & 25000 \\
\hline \multicolumn{5}{|c|}{ Pendapatan dan Keuntungan } \\
\hline 8 & Harga input bahan baku (Rp/Kg) & 9000 & 7500 & 5000 \\
\hline 9 & Sumbangan input lain $(\mathrm{Rp} / \mathrm{Kg})$ & 2000 & 3000 & 200 \\
\hline 10 & Nilai Output $(\mathrm{Rp} / \mathrm{Kg})$ & 31250 & 30000 & 52000 \\
\hline \multirow[t]{2}{*}{11} & Nilai Tambah (Rp/Kg) & 20250 & 19500 & 46800 \\
\hline & Rasio Nilai Tambah (\%) & 64,80 & 65,00 & 90,00 \\
\hline \multirow[t]{2}{*}{12} & Imbalan Tenaga Kerja (Rp/Kg) & 1333 & 1313 & 1667 \\
\hline & Bagian Tenaga Kerja (\%) & 6,58 & 6,73 & 3,56 \\
\hline \multirow[t]{2}{*}{13} & Keuntungan $(\mathrm{Rp} / \mathrm{Kg})$ & 18916,67 & 18187,50 & 45133,33 \\
\hline & Bagian keuntungan (\%) & 60,53 & 60,63 & 86,79 \\
\hline \multicolumn{5}{|c|}{ Balas Jasa untuk Faktor Produksi } \\
\hline \multirow[t]{4}{*}{14} & Marjin $(\mathrm{Rp} / \mathrm{Kg})$ & 22250,00 & 22500,00 & 47000,00 \\
\hline & a. Pendapatan Tenaga Kerja (\%) & 5,99 & 5,83 & 3,55 \\
\hline & b. Sumbangan input lain (\%) & 3086,42 & 4615,38 & 222,22 \\
\hline & c. Keuntungan $(\%)$ & 85,02 & 80,83 & 96,03 \\
\hline
\end{tabular}

Dari Tabel diatas menunjukkan bahwa masing-masing bahan baku dari tanaman obat-obatan dapat menjadi produk olahan yang mempunyai nilai tambah yang berbeda-beda. Hal ini terlihat dari bahan baku jahe yang dijadikan sebagai sirup jahe dengan nilai tambah sebesar Rp 20250,-/kg dengan rasio nilai tambah sebesar 64,80\% dari bahan baku yang diolah. Sedangkan bahan baku kunyit yang dijadikan sebagai produk Jamu kunyit memperolah nilai tambah sebesar Rp.19500,-/kg, dengan rasio nilai tambah 65,00\%. Adapun bahan baku pandan yang dijadikan produk pewarna pandan memperoleh nilai tambah sebesar Rp.46800,-/kg dengan rasio nilai tambah $90.00 \%$. Dari tabel tersebut dapat diketahui bahwa bagian tenaga kerja didalam agroindustri produk olahan dari tanaman obat-obatan prosentase tertinggi bila tanaman Kunyit diolah menjadi Jamu yaitu 6,73\%, kemudian diikuti dengan tanaman Jahe diolah menjadi Sirup Jahe yaitu $6,58 \%$, selanjutnya tanaman pandan diolah menjadi pewarna sebesar $3,56 \%$. Hal ini menunjukkan bahwa semakin tinggi prosentase berarti semakin besar pula bagian tenaga kerja dalam usaha agroindustri.

\section{IV.KESIMPULAN DAN SARAN}

\section{A. Kesimpulan}

Dari penelitian yang telah dilakukan dapat disimpulkan sebagai berikut :

1. Identifikasi jenis tanaman obat-obatan (toga) yang di tanam pada pekarangan sebagai pendukung bahan baku agroindustri yaitu:

Tanaman Obat-obatan (TOGA) yang teridenfikasi sejumlah 15 jenis tanaman obat-obatan, dari jumlah tersebut semua jenis tanaman obat-obatan dapat digunakan sebagai bahan baku agroindustri yaitu Jahe, Kunyit, Sere, Pandan, Lengkuas, Lidah Buaya, Kencur, Sirih, Kumis kucing, Tapak Doro, Temu lawak, Temu Ireng, Kunci, Keji beling, Sambiroto

2. Setelah dilakukan uji MPE masing-masing daerah penelitian mempunyai prioritas unggulan jenis tanaman yang digunakan sebagai bahan baku yang berbeda-beda, dari 3 urutan prioritas yang tertinggi yaitu:

a. Kabupaten Ngawi, unggulan tanaman obat-obatan adalah Jahe, Kunyit, Sere.

b. Kabupaten Magetan, unggulan tanaman obat-obatan adalah Jahe, Kunyit, Pandan.

c. Kabupaten Madiun, unggulan tanaman obat-obatan adalah Jahe, Lengkuas, Kunyit.

d. Kota Madiun, unggulan tanaman obat-obatan adalah Jahe, Pandan, Sere.

3. Nilai tambah yang diperoleh Tanaman Obat-obatan yang diproduksi menjadi produk olahan, untuk tanaman Jahe menjadi Sirup Jahe sebesar Rp.20250,-/kg, tanaman Kunyit menjadi Jamu Kunyit sebesar Rp.19500,-/kg, tanaman Pandan menjadi produk olahan Pewarna Pandan sebesar Rp.46800/kg.

\section{B. Saran}

Untuk pengembangan budidaya tanaman Obat-obatan di pekarangan tetap berlanjut maka perlu dilakukan hal-hal sebagai berikut :

- Sosialisasi yang berkelanjutan tentang pentingnya atau manfaat tanaman obat-obatan bagi kesehatan.

- Pemahaman dan keahlian tentang budidaya tanaman obat-obatan sehingga dapat melakukan sendiri bertanam tanaman obatobatan di pekarangan.Peningkatan pengetahuan tentang produk olahan tanaman obat-obatan sehingga dapat diperoleh nilai tambah. 
Website : http://agritek.unmermadiun.ac.id/index.php/agritek

\section{DAFTAR PUSTAKA}

Afifah, Anni. 2017. Analisis Efisiensi Penggunaan Faktor-Faktor Produksi Pada Usahatani Kentang di Kecamatan Batur, Kabupaten Banjarnegara.

T. Bantacut, "Pembangunan Ketahanan Ekonomi dan Pangan Perdesaan Mandiri Berbasis Nilai Tambah," J. Pangan, vol. 22, no. 2, pp. 397-406, 2013.

A. Setiyanto, "Approach and Implementation of Priority Agricultural Commodity Zone Development," Forum Penelit. Agro Ekon., vol. 31 No 2, no. Tanaman Pangan, pp. 171-195, 2013.

R. OELVIANI, "Sistem pertanian terpadu di lahan pekarangan mendukung ketahanan pangan keluarga berkelanjutan: Studi kasus di Desa Plukaran, Kecamatan Gembong, Kabupaten Pati, Jawa Tengah,” vol. 1, no. Hanani 2012, pp. 1197-1202, 2015.

I. D. A. Bgs, E. K. A. Artika, I. D. A. Ayu, and K. Marini, “ANALISIS NILAI TAMBAH ( VALUE ADDED ) BUAH PISANG MENJADI KRIPIK PISANG DI KELURAHAN BABAKAN KOTA MATARAM ( Studi Kasus Pada Industri Rumah Tangga Kripik Pisang Cakra ) PENDAHULUAN Latar Belakang Perumusan Masalah Tujuan Penelitian," GaneÇ Swara Vol., vol. 10, no. 1, pp. 94-98, 2016.

Suhartini, "PERAN KEANEKARAGAMAN TANAMAN DI LAHAN PEKARANGAN DALAM KEHIDUPAN MASYARAKAT KABUPATEN SLEMAN," vol. 23, no. 39870423, pp. 946-952, 2007.

R. M. Wardhani, I. R. Puspitawati, and L. Belakang, "Nilai tambah mocaf pada agroindustri singkong sebagai upaya pemberdayaan sumberdaya lokal," no. 2006,2014

S. Murtiati, "Pekarangan Sebagai Pendongkrak Pendapatan Ibu Rumah Tangga di Kabupaten Boyolali," 2009.

Saragih, Pengembangan Agribisnis Dalam Pembangunan Ekonomi Nasional Menghadapi Abad ke-21. 1995.

U. Hasanah, F. Pertanian, and U. Gadjah, “Analisis Nilai Tambah Agroindustri Sale Pisang di Kabupaten Kebumen The Value Added Analysis of Sale Pisang Agroindustry in Kebumen Regency," vol. 18, no. 3, pp. 141-149, 2015.

W. RM, "Peranan agroindustri dalam meningkatkan nilai tambah komoditi pisang, nangka dan garut,” Agritek, vol. 11, no. 1 Maret, pp. 45-52, 2010.

[Wardhani, R.M,1999 Analisa Nilai Tambah Komoditi Melinjo pada Agroindustri Emping Melinjo di Kabupaten Madiun.

-, dan Puspitawati ,IR,2004 Analisa Faktor-faktor yang mempengaruhi Curahan Tenaga Kerja Wanita Pada Agroindustri Emping Garut di Kecamatan Kare Kabupaten Madiun. --, 2007. Peranan Agroindustri Dalam Meningkatkan Nilai Tambah Komoditas pisang,Nangka dan Garut. 